\title{
Calprotectin and necrotizing enterocolitis: it's not the assay, it's the definition
}

\author{
Jonathan R. Swanson ${ }^{1}$
}

Received: 22 June 2018 / Accepted: 16 July 2018 / Published online: 14 August 2018

(c) Springer Nature America, Inc. 2018

Distinguishing necrotizing enterocolitis (NEC) from other disease entities has been a conundrum over the last several decades within the field of neonatology. Bell et al. [1] were the first to attempt to characterize the differences in NEC phenotypes and despite the inadequacies of the current definition(s) of NEC, Bell's Staging Criteria continue to be used [2-5]. Unfortunately, only limited data prove these inadequacies to be true. Spontaneous intestinal perforation (SIP) is the classic example. Once a nearly $15 \%$ contaminate of NEC datasets, its recognition and exclusion as a separate disease has markedly improved the quality of NEC data. It is the clearest example of what has been called the subset approach to NEC reduction [6]. As we continue to understand NEC subsets better, some will turn out to be different diseases entirely, like SIP, whereas others will prove to be distinct NEC variants that have demonstrably different risk factors for development of NEC and different outcomes [7-10].

In this month's issue of the Journal of Perinatology, MacQueen et al. [11] do an excellent job of demonstrating why diagnostic assays for NEC will not work until we understand not all NEC is the same disease and use NEC subsets for categorization. Previous research has demonstrated that calprotectin, an antibacterial protein, that is released from activated macrophages and neutrophils is generally increased in the stool of neonates with NEC compared to those without disease [12-14]. However, nearly all of these prior studies were limited in that they compared infants with diseased bowel to healthy term newborns. In a recent prospective study on the utility of using serial fecal calprotectin, van Zoonen et al. [15] concluded that due to such wide variation in levels during the

Jonathan R. Swanson

jswanson@virginia.edu

1 Department of Pediatrics, University of Virginia Children's Hospital, Charlottesville, VA, USA first weeks after birth, fecal calprotectin was not a useful test to predict the onset of NEC. MacQueen et al.'s study attempts to solve these issues by creating a gestational age appropriate control group.

The authors took nearly 250 stool samples from 120 infants between 1 and 8 weeks of age to create a reference interval for fecal calprotectin. This allowed them to develop 10th and 90th percentile values by gestational age. In the second part of the study, the authors plotted 5 years of data points where fecal calprotectin was measured in infants who were being evaluated for NEC by the bedside clinician. As noted by the authors, these samples were typically sent when the diagnosis of NEC was raised, but not in cases where the clinician felt reasonably certain through radiographic or other clinical findings. Their preliminary finding was not very compelling. The fit under the receiving operating characteristic curve was $<0.8$. However, the authors had included all gestations, including those who were term.

It should be noted that Robert Christensen and his colleagues have published more literature on term NEC that anyone else in the post-surfactant era. His findings suggest that term infants with NEC almost always have some identifiable intestinal or systemic ischemic precondition before they acquire NEC [16]. The point here is that term NEC is fundamentally different from preterm NEC, which likely arises from events that lead to intestinal dysbiosis [17]. It stands to reason that term infants might act like a distinct subgroup. That is exactly what MacQueen et al. observed. When they only looked at infants $<35$ weeks, the receiving operating characteristic curve rounded to 0.9. Exclusion of the term NEC subgroup dramatically improved the fit.

There is reason to believe that there may be one or more other subgroups within the preterm NEC cohort that adversely affects the reliability of calprotectin. MacQueen et al. [14] have previously reported that infants with bloody stools who did not progress to NEC had relatively low calprotectin levels. Likewise, in a previous publication, 
Christensen et al. [18] reported that nearly half of all infants presenting with bloody stools had eosinophilia. These findings suggest another subgroup of NEC that has been emerging within both neonatology and pediatric gastroenterology. The diagnoses within this group include: food protein-induced enterocolitis (FPIES), eosinophilic gastrointestinal disease (EGID) and cow's milk protein intolerance (CMPI). Case and cohort studies indicate that such patients can progress to NEC [19-22]. Within NEC datasets, it is estimated that more than $5 \%$ of all cases are from this subgroup [20, 23]. Their progression is relatively indolent and the prognosis is much better than typical preterm NEC. Most importantly, this subset of patients likely adversely affects the accuracy of calprotectin in a preterm NEC cohort.

Why does any of this matter? Because NEC data are "dirty". They have been for decades. The removal of SIP was the first real step towards improving the definition of NEC (and thus the data) in the post-surfactant era. More recently, we have seen the categorical exclusion of term infants and congenital anomalies from preterm NEC as a further cleansing measure. However, MacQueen and her colleagues have (perhaps unintentionally) demonstrated why it is not enough to just take a knife to the data post hoc. We must evaluate NEC subgroups. It's time for us to listen to what the data are telling us. It's time to redefine NEC.

\section{Compliance with ethical standards}

Conflict of interest The author declares that he has no conflict of interest.

\section{References}

1. Bell MJ, Ternberg JL, Feigin RD, Keating JP, Marshall R, Barton $\mathrm{L}$, et al. Neonatal necrotizing enterocolitis: therapeutic decisions based upon clinical staging. Ann Surg. 1978;187:1-7.

2. Kliegman RM, Walsh MC. Neonatal necrotizing enterocolitis: pathogenesis, classification, and spectrum of disease. Curr Probl Pediatr. 1987;17:243-88.

3. Gordon PV, Swanson JR, Attridge JT, Clark R. Emerging trends in acquired neonatal intestinal disease: is it time to abandon Bell's criteria? J Perinatol. 2007;27:661-71.

4. Gordon PV, Swanson JR, MacQueen BC, Christensen RD. A critical question for NEC researchers: can we create a consensus definition of NEC that facilitates research progress? Semin Perinatol. 2017;41:7-14.

5. Gephart SM, Gordon PV, Penn AH, Gregory KE, Swanson JR, Maheswari A, et al. Semin Pediatr Surg. 2018;27:3-10.

6. Gordon PV, Swanson JR. Necrotizing enterocolitis is one disease with many origins and potential means of prevention. Pathophysiology. 2014;21:13-9.
7. Hull MA, Fisher JG, Gutierrez IM, Jones BA, Kang KH, Kenny $\mathrm{M}$, et al. Mortality and management of surgical necrotizing enterocolitis in very low birth weight neonates: a prospective cohort study. J Am Coll Surg. 2014;218:1148-55.

8. Swanson JR. Surgical necrotizing enterocolitis: time for a definition. J Am Coll Surg. 2015;220:370.

9. Gordon PV, Attridge JT. Understanding clinical literature relevant to spontaneous intestinal perforations. Am $\mathrm{J}$ Perinatol. 2009;26:309-16.

10. Shin SH, Kim EK, Yoo H, Choi YH, Kim S, Lee BK, et al. Surgical necrotizing enterocolitis versus spontaneous intestinal perforation in white matter injury on brain magnetic resonance imaging. Neonatology. 2016;110:148-54.

11. MacQueen BC, Christensen RD, Yost CC, Gordon PV, Baer VL, Schlaberg R, et al. Reference intervals for stool calprotectin in preterm neonates and their utility for the diagnosis of necrotizing enterocolitis. J. Perinatol. 2018. https://doi.org/10.1038/s41372018-0108-9.

12. Carroll D, Corfield A, Spicer R, Cairns P. Faecal calprotectin concentrations and diagnosis of necrotizing enterocolitis. Lancet. 2003;361:310-1.

13. Bin-Nun A, Booms C, Sabag N, Mevorach R, Algur N, Hammerman C. Rapid fecal calprotectin (FC) analysis: point of care testing for diagnosing early necrotizing enterocolitis. Am J Perinatol. 2015;32:337-42.

14. MacQueen BC, Christensen RD, Yost CC, Lambert DK, Baer VL, Sheffield MJ, et al. Elevated fecal calprotectin levels during necrotizing enterocolitis are associated with activated neutrophils extruding neutrophil extracellular traps. J Perinatol. 2016;36:862-9.

15. Van Zoonen AGJF, Hulzebos CV, Muller Kobold AC, Kooi EMW, Bos AF, Hulscher JBF. Serial fecal calprotectin in the prediction of necrotizing enterocolitis in preterm neonates. $\mathrm{J}$ Pediatr Surg. 2018. pii: S0022-3468(18)30308-7.

16. Christensen RD, Lambert DK, Baer VL, Gordon PV. Necrotizing enterocolitis in term infants. Clin Perinatol. 2013;40:69-78.

17. Pammi M, Cope J, Tarr PI, Warner BB, Marrow AL, Mai V, et al. Intestinal dysbiosis in preterm infants preceding necrotizing enterocolitis: a systemic review and meta-analysis. Microbiome. 2017;5:31.

18. Christensen RD, Lambert DK, Gordon PV, Baer VL, Gerday E, Henry E. Neonates presenting with bloody stools and eosinophiia can progress to two different types of necrotizing enterocolitis. J Perinatol. 2012;32:874-9.

19. Leonard SA, Pecora V, Fiocchi AG, Nowak-Wegrzyn A. Food protein-induced enterocolitis syndrome: a review of the new guidelines. World Allergy Organ J. 2018;11:4.

20. Lenfestey MW, de la Cruz D, Neu J. Food protein-induced enterocolitis instead of necrotizing enterocolitis? A neonatal intensive care unit case series. J Pediatr. 2018. pii: S0022-3476 (18)30602-4.

21. Srinivasan P, Brandler M, D'Souza A, Millman P, Moreau H. Allergic enterocolitis presenting as recurrent necrotizing enterocolitis in preterm neonates. J Perinatol. 2010;30: 431-3.

22. Cordova J, Sriram S, Patton T, Jericho H, Gokhale R, Weinstein $\mathrm{D}$, et al. Manifestations of cow's-milk protein intolerance in preterm infants. JPGN. 2016;62:140-4.

23. Gordon PV, Clark R. In response to the case report of allergic enterocolitis in a preterm neonate: how prevalent is systemic eosinophilia with NEC? J Perinatol. 2011;31:297-8. 